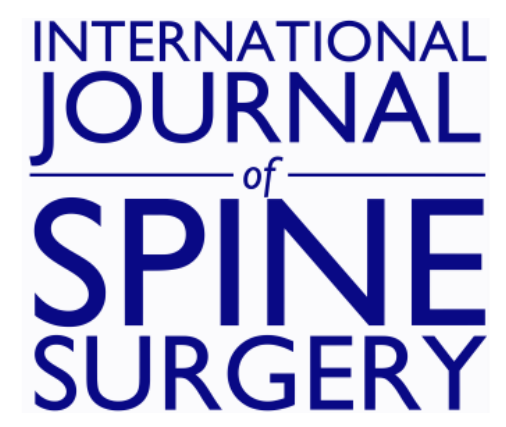

\title{
Contribution of Round vs. Rectangular Expandable Cage Endcaps to Spinal Stability in a Cadaveric Corpectomy Model
}

Gregory M. Mundis, Robert K. Eastlack, Payam Moazzaz, Alexander W. L. Turner and G. Bryan Cornwall

Int J Spine Surg 2015, 9 ()

doi: https://doi.org/10.14444/2053

http://ijssurgery.com/content/9/53

This information is current as of April 25, 2023.

Email Alerts Receive free email-alerts when new articles cite this article. Sign up at:

http://ijssurgery.com/alerts

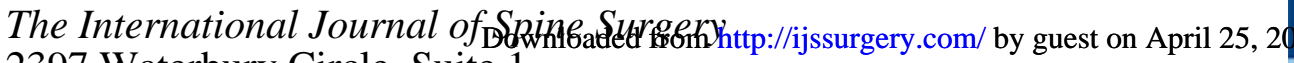
2397 Waterbury Circle, Suite 1,

Aurora, IL 60504, Phone: +1-630-375-1432

(C) 2015 ISASS. All Rights Reserved. 


\section{Contribution of Round vs. Rectangular Expandable Cage Endcaps to Spinal Stability in a Cadaveric Corpectomy Model}

Gregory M. Mundis, MD,1,2 Robert K. Eastlack, MD,1,2 Payam Moazzaz, MD, ${ }^{3}$ Alexander W. L. Turner, PhD, ${ }^{4}$ G. Bryan Cornwall PhD 4

${ }^{1}$ Scripps Clinic Division of Orthopedic Surgery, San Diego, CA; ${ }^{2}$ San Diego Spine Foundation, San Diego, CA; ${ }^{3}$ Orthopaedic Specialists of North County, Tri-City Medical Center Orthopaedic and Spine Institute, Oceanside, CA; ${ }^{4}$ NuVasive, Inc., San Diego, CA

\section{Abstract}

\section{Background}

Expandable cages are gaining popularity in anterior reconstruction of the thoracolumbar spine following corpectomy as they can provide adjustable distraction and deformity correction. Rectangular, rather than circular, endcaps provide increased resistance to subsidence by spanning the apophyseal ring; however their impact on construct stability is not known. The objective of this study was to investigate the contribution of expandable corpectomy cage endcap shape (round vs. rectangular) and fixation method (anterior plate vs. posterior pedicle screws) to the stability of an L1 sub-total corpectomy construct.

\section{Methods}

Eight fresh-frozen cadaveric specimens (T11-L3) were subjected to multi-directional flexibility testing to $6 \mathrm{~N} \cdot \mathrm{m}$ with a custom spine simulator. Test conditions were: intact, L1 sub-total corpectomy defect, expandable cage (round endcap) alone, expandable cage (round endcap) with anterior plate, expandable cage (round endcap) with bilateral pedicle screws, expandable cage (rectangular endcap) alone, expandable cage (rectangular endcap) with anterior plate, expandable cage (rectangular endcap) with bilateral pedicle screws. Range-of-motion across T12-L2 was measured with an optoelectronic system.

Results

The expandable cage alone with either endcap provided significant stability to the corpectomy defect, reducing motion to intact levels in flexion-extension with both endcap types, and in lateral bending with rectangular endcaps. Round endcaps allowed greater motion than intact in lateral bending, and axial rotation ROM was greater than intact for both endcaps. Supplemental fixation provided the most rigid constructs, although there were no significant differences between instrumentation or endcap types.

\section{Conclusions}

These results suggest anterior-only fixation may be adequate when using an expandable cage in a sub-total corpectomy application and choice of endcap type may be driven by other factors such as subsidence resistance.

KEYWORDS: CORPECTOMY, EXPANDABLE CAGE, ENDCAP SHAPE, BIOMECHANICS, STABILITY

VOLUME 9 ARTICLE 53 DOI: 10.14444/2053

\section{Introduction}

There is an increasing interest in less invasive, direct lateral approaches to the thoracolumbar spine to treat pathology including trauma, tumors, and infection. The potential benefits of this approach include decreased perioperative morbidity and pain, expedited ambulation, and earlier discharge from the hospital. ${ }^{1-8}$

Vertebral body involvement by trauma, tumors, and infections often necessitate corpectomy and canal decompression followed by spinal reconstruction and Downloaded from http://ijssurgery.com/by guest on April 25, 2023 stabilization. Expandable corpectomy cages are gaining popularity in reconstructive procedures of the thoracolumbar spine, as newer cage designs allow for the adjustment of cage height in situ to provide controlled distraction and deformity correction.

There are several surgical techniques currently used to treat instability of the thoracolumbar spine including anterior-alone fixation, posterior fixation, or combined anterior-posterior fixation. However, the effects of these various spinal fusion constructs on spinal stiffness have not been clearly defined, and the 
strengths and weaknesses of each technique are still controversial. ${ }^{9}$ Biomechanical analysis of these surgical techniques is needed to enable selection of the appropriate surgical method for restoration of spinal stability and successful spinal fusion.

While the ability to restore anterior column support with an expandable cage is appealing, the optimum cage design and endcap footprint have not been determined. Smaller, cylindrical footprint designs have been associated with subsidence and loss of deformity correction..$^{10}$ Larger, rectangular endcaps have been shown to increase resistance to subsidence by traversing the width of the vertebral body to rest on the apophyseal ring (Figure 1). ${ }^{11,12}$ The apophyseal ring has been shown to possess the strongest and most dense vertebral body endplate bone. ${ }^{13}$ In addition to reducing the likelihood of subsidence, rectangular endcaps for an interbody expandable device have been proposed to provide a more stable construct for anterior column support. This proposal is based on previous demonstration that larger footprint intervertebral implants and those that span the apophyseal ring resulted in greater stability, potentially due to the implant shape helping to block motion. $^{14}$

Sasso et al. ${ }^{15}$ demonstrated successful treatment with decompression and fusion of three-column thoracolumbar fractures in 95\% of patients using anterioronly reconstruction. While the use of anterior-only fixation is attractive and minimizes the increased risk and surgical time of a second stage procedure, the biomechanical implications of this method have not been fully demonstrated. This study investigates the contribution of the endcap shape (round vs. rectangular) and fixation method (anterior plate vs. posterior pedicle screws) to the stability of an L1 corpectomy reconstruction in a cadaveric model.

\section{Materials And Methods}

\section{Specimen Preparation}

Eight fresh-frozen male cadaveric specimens (average age: 45.5 , range: $29-62$ yrs) were dissected, retaining the ligaments and intervertebral discs. Bone mineral density was measured by standard lumbar anterior-posterior (A-P) dual-energy x-ray absorp- tiometry (average: $0.887 \mathrm{~g} / \mathrm{cm}^{2}$, range: $0.764-1.045$ $\left.\mathrm{g} / \mathrm{cm}^{2}\right)$. The specimens were potted in polyurethane resin (Smooth-Cast ${ }^{\circledR}$ 300; Smooth-On, Inc. Macungie, PA) at T11 and L3. Prior to mounting on the testing system, 2 lateral bolts $(6.5 \mathrm{x} 45$ or $50 \mathrm{~mm})$ for the 2 bolt $/ 2$ screw anterior plate (Traverse ${ }^{\circledR}$; NuVasive, Inc., San Diego, CA) were placed at T12 and L2 according to the prescribed surgical technique. In addition, $5.5 \times 40$ or $45 \mathrm{~mm}$ polyaxial pedicle screws (Armada ${ }^{\circledR} ;$ NuVasive, Inc.) were placed bilaterally, without connecting rods, at $\mathrm{T} 12$ and $\mathrm{L} 2$ taking care to avoid damage to the facet capsules. Infrared LED marker arrays were placed at $\mathrm{T} 12$ and L 2 for motion capture purposes.

\section{Experimental Protocol}

Each specimen was tested on a custom 6 degrees-offreedom spine test system (Figure 2) described previously, ${ }^{16}$ using three cycles each of unconstrained 6.0 N.m moments in flexion-extension, left-right lateral bending, and left-right axial rotation. No axial load was applied. Test parameters were based on the quasi-static load testing performed by Hitchon et al. ${ }^{17}$

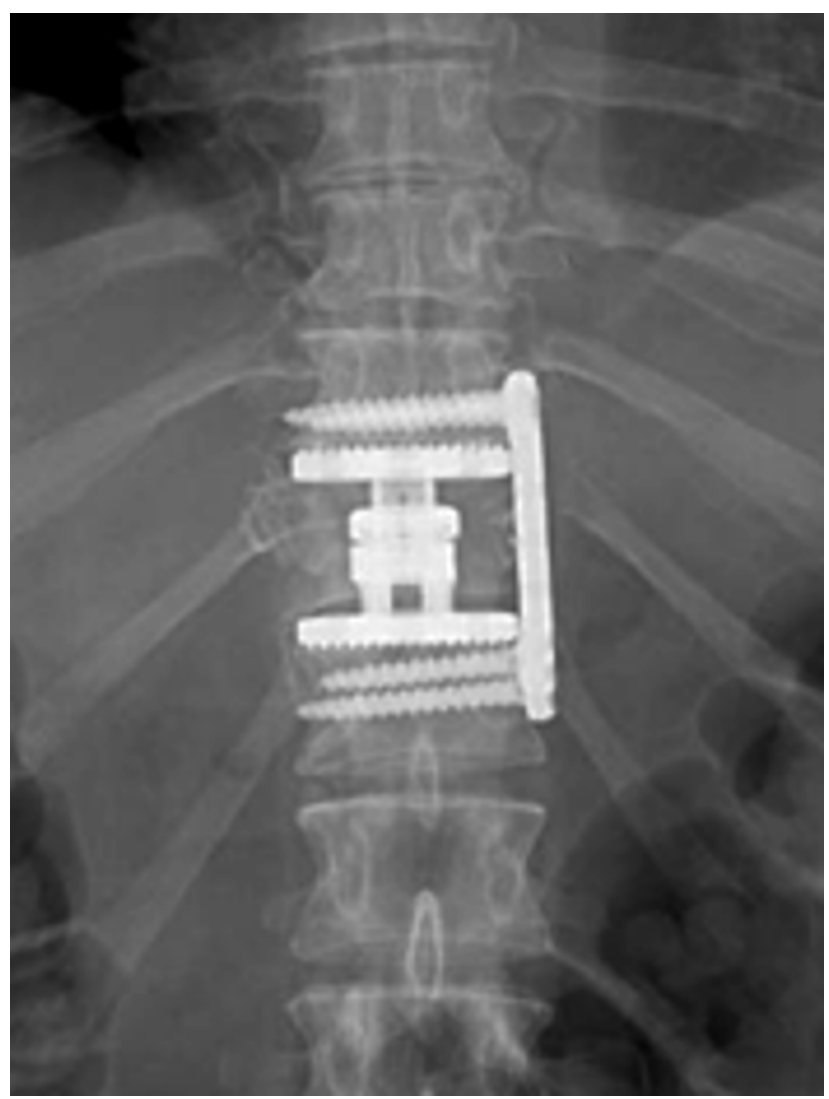

Fig. 1. A-P radiograph showing expandable corpectomy cage with rectangular endcaps spanning the ring apophysis. 
After testing the intact spine (A), the following conditions were evaluated: (B) L1 sub-total corpectomy defect, (C) expandable cage (round endcaps) alone, (D) expandable cage (round endcaps) with anterior plate, (E) expandable cage (round endcaps) with bilateral pedicles screws, $(\mathrm{F})$ expandable cage (rectangular endcaps) alone, $(\mathrm{G})$ expandable cage (rectangular endcaps) with anterior plate, and $(\mathrm{H})$ expandable cage (rectangular endcaps) with bilateral pedicle screws (Figure 3). Sequence randomization was used with the order of testing of round and rectangular endcaps. The testing sequence was $(\mathrm{A}-\mathrm{H})$ for 4 of the specimens, and (A, B, F-H, C-E) for the other 4 .

The L1 sub-total corpectomy defect was approximately $26 \mathrm{~mm}$ in A-P width and spanned the lateral width of the T12 and L2 endcaps. The T12-L1 and L1-L2 discs and cartilaginous endcaps within the 26 $\mathrm{mm}$ space were excised while the anterior and posterior longitudinal ligaments were preserved.

The modular expandable cage $\left(\mathrm{X}-\mathrm{CORE}^{\circledR}, \mathrm{NuVa}-\right.$ sive, Inc.) is available with round or rectangular endcaps in flat or lordotic configurations. The largest diameter round endcaps $(26 \mathrm{~mm})$ were tested in conditions (C-E), while the smallest A-P width rectangular endcaps $(18 \mathrm{~mm})$ were used in conditions $(\mathrm{F}-\mathrm{H})$, with lateral length (40 or $50 \mathrm{~mm}$ ) selected to span the width of the vertebral body. The endcaps were secured to the expandable core of appropriate height

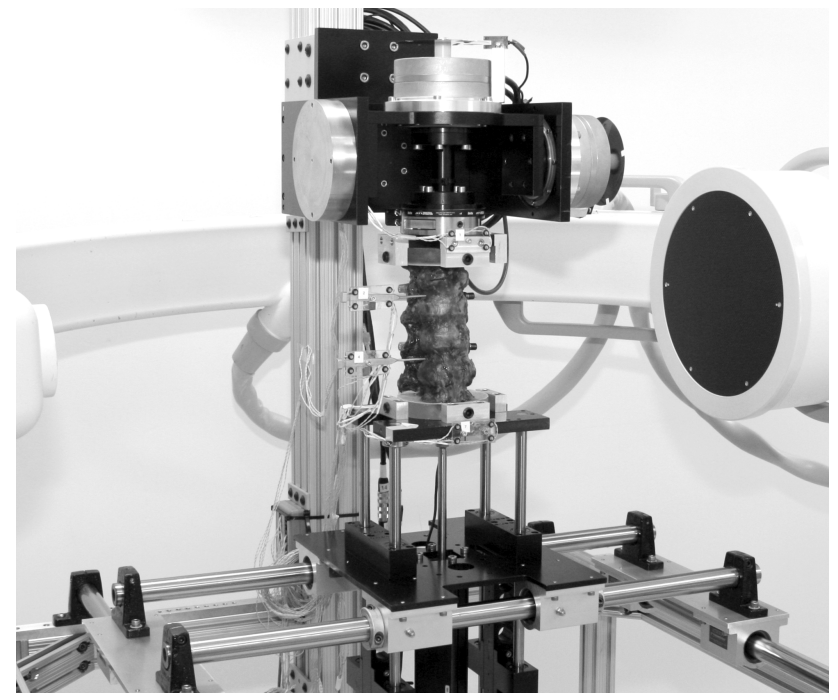

Fig. 2. Experimental test setup showing T11-L3 intact spine mounted on multiaxial spine test system. Infrared LED marker arrays attached at T12 and L2.
(28-40 $\mathrm{mm}$ or $35-52 \mathrm{~mm})$. The expandable cages were deployed using a digital torque meter to ensure uniform distraction forces. The largest diameter round endcaps and smallest A-P width rectangular endcaps were selected in order to not bias the data towards the rectangular endcaps.

The anterior plate conditions ( $D$ and $G$ ) consisted of a 2 bolt/ 2 screw titanium alloy compression plate applied over the expandable cage. An appropriately sized plate was positioned over the previously placed bolts and lock nuts were tightened to the manufacturer-specified torque. The two $5.5 \mathrm{~mm}$ diameter anterior screws (lengths $35-45 \mathrm{~mm}$ ) were subsequently driven through the plate to lag it down to the bone. For the bilateral pedicle screw fixation conditions $(\mathrm{E}$ and $\mathrm{H})$, the anterior screws and plate were removed, leaving the 2 bolts in place, and the T11 and L2 pedicle screws were connected with bilateral $5.5 \mathrm{~mm}$ diameter titanium alloy rods.

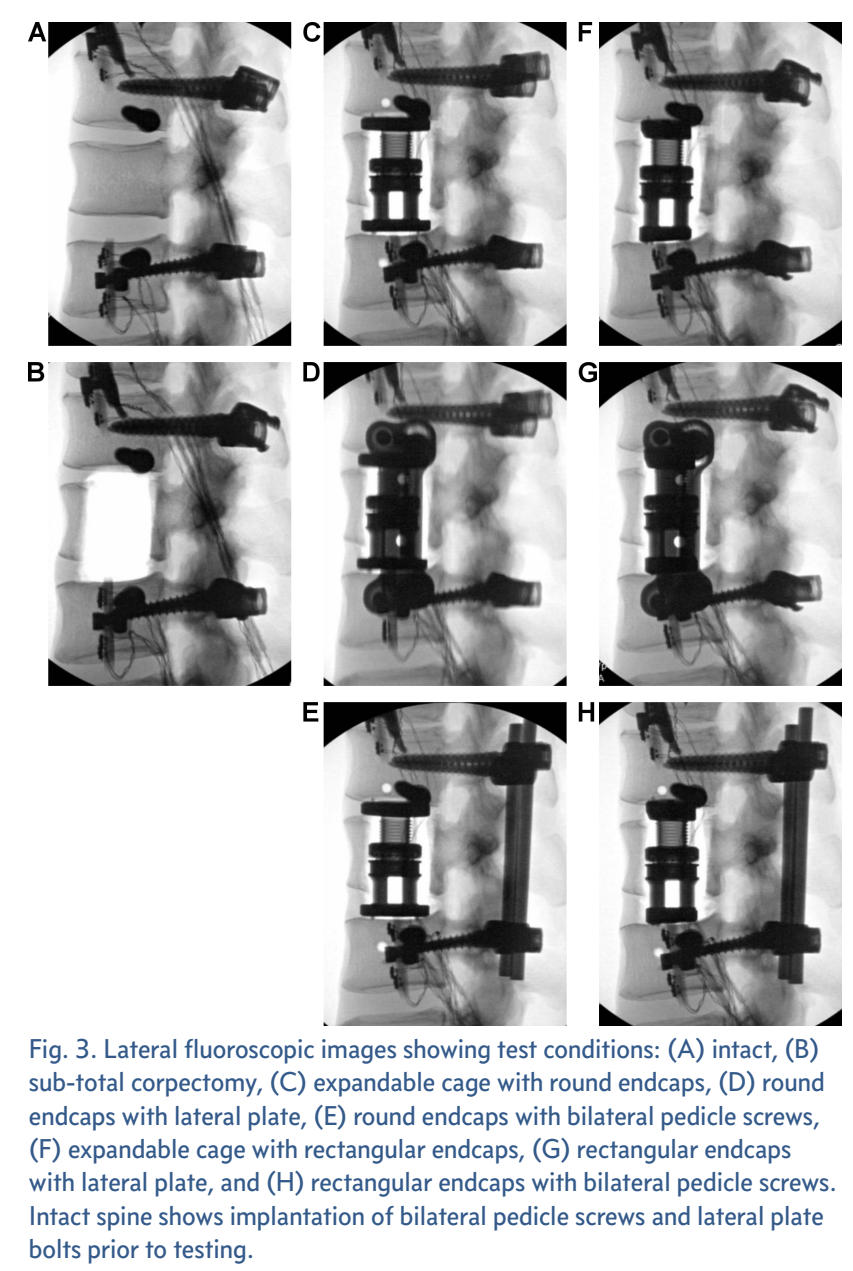


Data Analysis

The T12-L2 angular rotations were recorded using an Optotrak Certus ${ }^{\circledR}$ motion capturing system

(Northern Digital, Inc., Waterloo, Ontario, Canada).

Data from the third loading cycle in each motion direction was analyzed. Range of motion (ROM) was defined as the total angular displacement in the motion cycle, for example from flexion at $6.0 \mathrm{~N} \cdot \mathrm{m}$ to extension at $-6.0 \mathrm{~N} \cdot \mathrm{m}$. ROM across the corpectomy construct (T12 to L2) from each group was compared with repeated-measures ANOVA followed by Holm-Sidak comparisons. Statistical significance was defined as $\mathrm{p}<0.05$.

\section{Results}

T12-L2 range-of-motion (Figure 4A-C) was significantly increased following the corpectomy procedure, with the greatest increase in motion seen in axial rotation (flexion-extension: 2.2 times, lateral bending: 3.3 times, axial rotation: 11.7 times, $\mathrm{p}<0.001$; Table 1). In all motion planes tested, the expandable cage alone (round or rectangular endcaps) significantly reduced motion with respect to the corpectomy defect condition $(\mathrm{p}<0.001)$. Both expandable cage endcap designs without supplemental fixation demonstrated similar motion to the intact spine in flexion-extension (round: $\mathrm{p}=0.639$, rectangular: $\mathrm{p}=$ 0.589 ). In lateral bending, the rectangular endcap cage was not significantly different from intact $(\mathrm{p}=$ 0.999), while the round endcap cage alone allowed more motion than intact $(\mathrm{p}<0.001)$. Both endcap design cages without fixation allowed greater motion than intact in axial rotation $(\mathrm{p}<0.001)$.

Addition of supplemental fixation to the round endcap expandable cage increased rigidity and all statistical comparisons to this were significant $(p<0.001)$ with the exception of the cage with anterior plate in flexion-extension $(\mathrm{p}=0.054)$. Similarly for the rectangular endcap cage, addition of fixation significantly increased rigidity in all directions for both the anterior plate and pedicle screws $(\mathrm{p} \leq 0.050)$. For both endcap designs, pedicle screw fixation provided greater stability in flexion-extension compared with the anterior plate (round: $\mathrm{p}=0.526$, rectangular: $\mathrm{p}=$ 0.632 ), while anterior plating was more rigid than pedicle screws in axial rotation (round: $\mathrm{p}=0.751$, rec- tangular: $\mathrm{p}=0.910$ ); however none of these differences reached statistical significance. Furthermore, average axial rotation ROM did not reach below intact for either the anterior plate or pedicle screws. The two fixation methods were comparable in lateral bending (round: $\mathrm{p}=1.000$, rectangular: $\mathrm{p}=1.000$ ).

Comparing the two endcap designs directly without supplemental fixation, there was no significant differ-
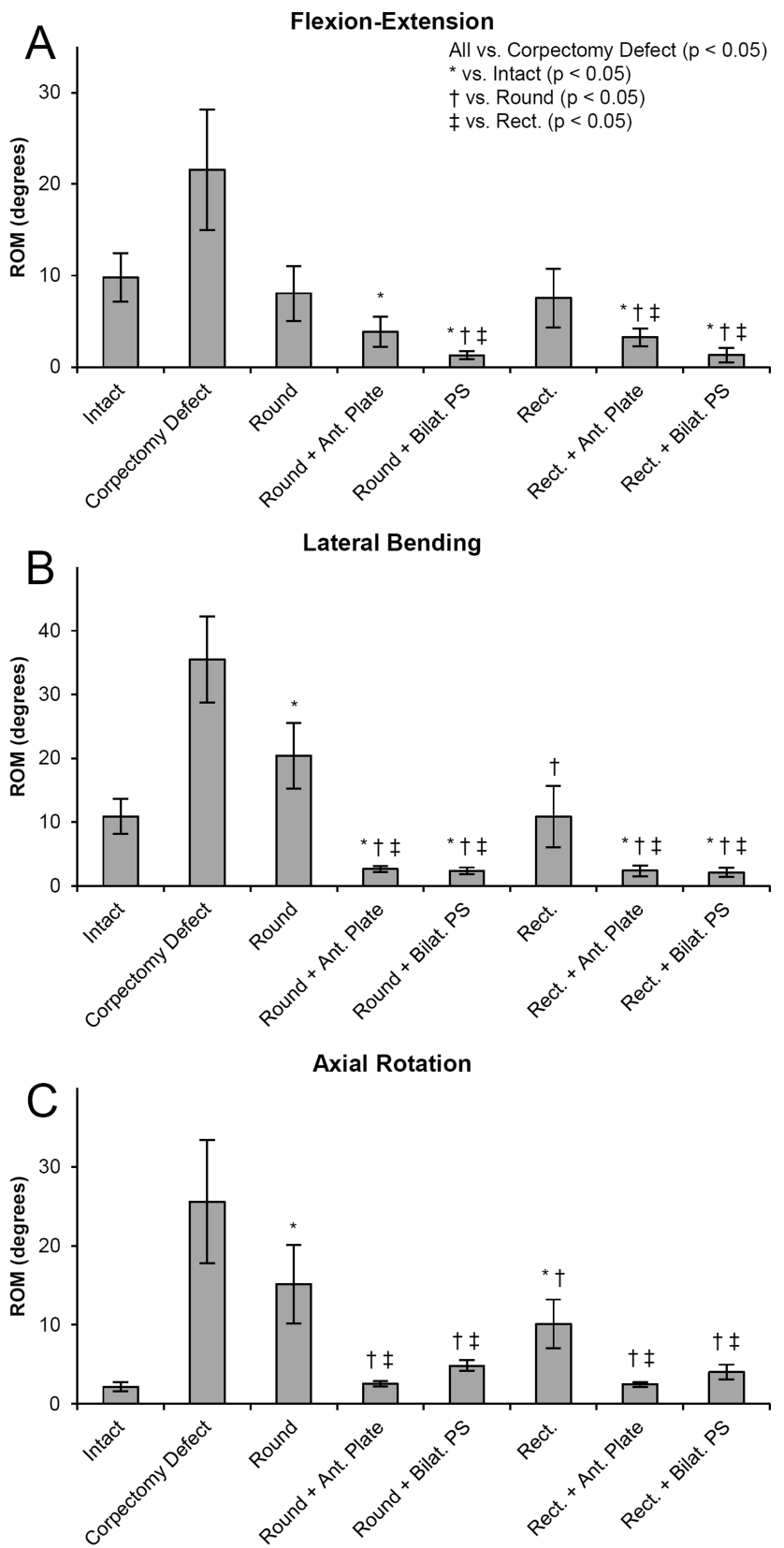

Fig. 4. Mean T12-L2 range of motion for all test conditions in: (A) flexion-extension, (B) lateral bending and (C) axial rotation. Error bars represent \pm 1 standard deviations. ROM denotes range of motion, Round expandable cage with round endcaps, Rect. - expandable cage with rectangular endcaps, Ant. Plate - anterior plate, Bilat. PS - bilateral pedicle screws. 
ence between the round or rectangular endcaps under flexion-extension $(\mathrm{p}=0.924)$, however in lateral bending the rectangular endcaps provided 1.9 times more stability than the round $(\mathrm{p}<0.001)$ and in axial rotation the rectangular endcaps increased stability by 1.5 times $(\mathrm{p}=0.026)$. When fixation was added, there were no statistically significant differences between the fixation or endcap types $(p \geq 0.497)$.

\section{Discussion}

The importance of anterior column support in thoracolumbar corpectomy reconstruction has previously been demonstrated. Addition of anterior support to

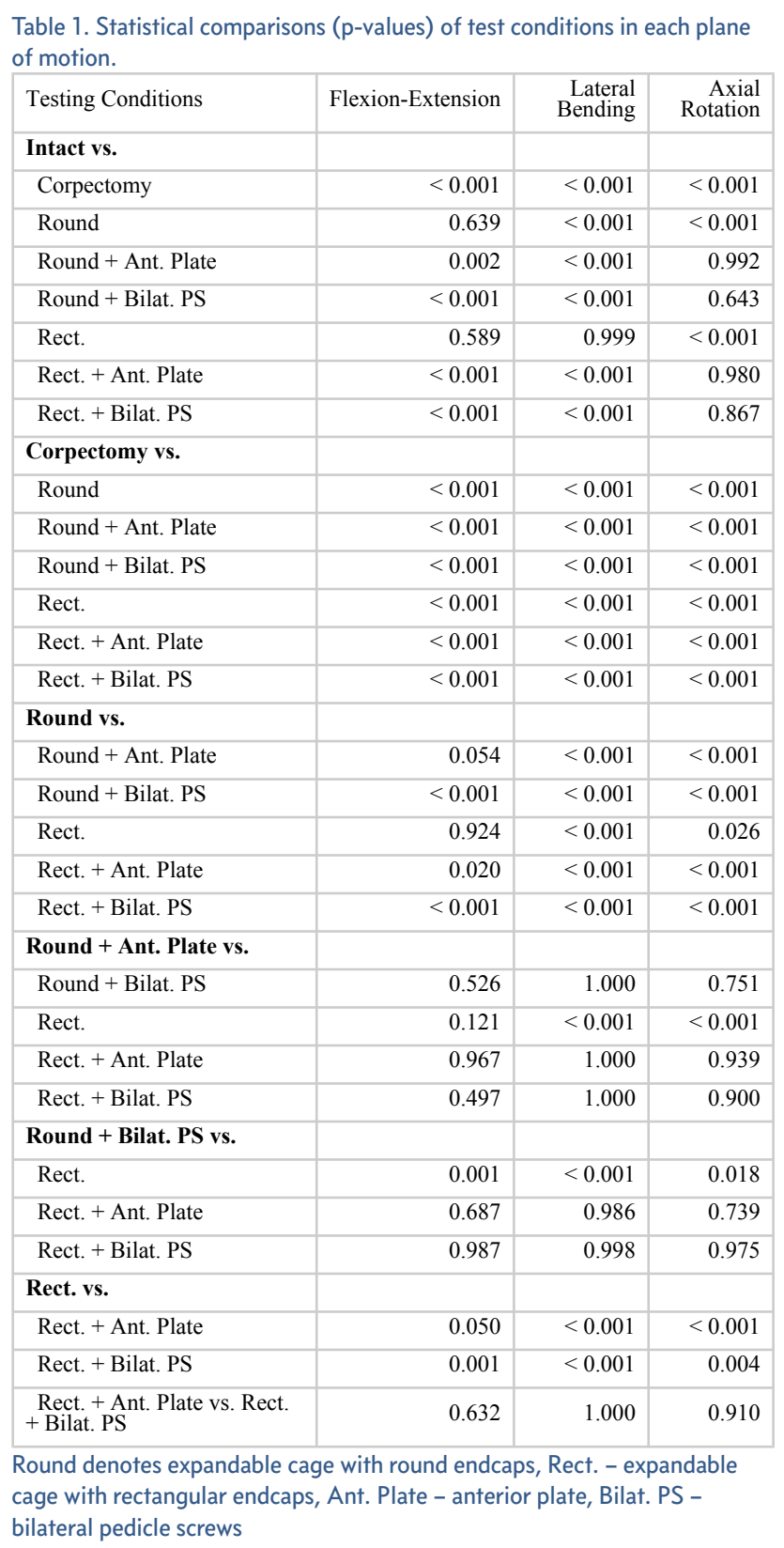

anterior, posterior or circumferential fixation devices significantly increases compression and lateral bending stiffness, and to a lesser extent, flexionextension..$^{18-22}$ The results of the current study also support the use of combined anterior column support and additional supplemental fixation for reconstruction following corpectomy. The expandable cages alone, with round or rectangular endcaps, were noted to provide substantial stability to the corpectomy defect, although not beyond that of the intact spine.

In the absence of supplemental fixation, we noted significant differences $(\mathrm{p} \leq 0.023)$ between the endcap types in lateral bending and axial rotation, with the rectangular endcap providing greatest stability. In flexion-extension, the results were similar between endcap types. The authors are not aware of previous studies investigating kinematics of different corpectomy cage types without supplemental fixation. However, studies have shown that the type of anterior support (strut, mesh, expandable cage), in the presence of supplemental fixation generally does not have a significant effect on the stability of the corpectomy reconstruction. ${ }^{19,23-25}$ Similar findings were observed in the current study, where there were no statistically significant differences between the round and rectangular endcap expandable cages with either anterior or posterior fixation. It is apparent that the rigidity of the supplemental fixation is the dominant factor influencing construct ROM, making it difficult to detect differences between the endcap types.

The fixation requirements for corpectomy reconstruction are not clearly defined, however some form of supplemental internal stabilization is always recommended. Some authors have advocated the use of anterior-only fixation in certain conditions, including up to three-column thoracolumbar injuries, as demonstrated with promising results in clinical studies. ${ }^{15,26-28}$ Conversely, Hitchon et al. ${ }^{29}$ recommend combined anterior-posterior fixation for threecolumn injuries. Anterior-only fixation has the advantage of being performed through the same surgical approach as the anterior column support; alleviating the need for a second posterior surgery and minimizing potential risks. Biomechanical stability of anterior fixation devices, in the form of anterolateral 
plate or dual-rod constructs, has been investigated in multiple studies, however results are mixed with respect to stability offered by different anterior devices and comparisons with posterior instrumentation.

Comparing between anterior fixation devices, most studies generally indicate rigidity similar to or exceeding the intact spine. Results are variable likely based on degree of destabilization, type of instrumentation, and differences in test methods. In the current study, we found that with supplemental anterior fixation, there was a significant reduction in flexion-extension and lateral bending ROM, while axial rotation ROM was not reduced relative to the intact specimen. Hitchon et al. ${ }^{30}$ evaluated an anterior plate with constrained screws to supplement an L1 sub-total corpectomy. The instrumentation reduced flexion-extension and lateral bending significantly with respect to intact. Axial rotation motion was greater than intact, but there was no significant difference. They recommended a device that includes four bicortical, constrained screws to maximize rigidity, similar to the findings of Disch et al. ${ }^{31}$ Postoperative bracing was suggested to restrict axial rotation since the results showed higher ROM than intact in that plane. Disch et al. ${ }^{31}$ discovered that an angular stable plate system provided superior stability over a polyaxial system after fatigue loading in spine with expandable cage and L1 total corpectomy. The angular-stable plate was more rigid than the polyaxial in lateral bending; and both allowed less motion than intact. However, neither plate system achieved intact stability in axial rotation. In addition, both plates were less rigid than intact in flexion-extension. Chang et al..$^{32}$ found improved stability with respect to intact in all directions except extension, but detected no significant differences between stability of $5.5 \mathrm{~mm}$ diameter and $6.35 \mathrm{~mm}$ diameter dual-rod constructs in a total T11 corpectomy. Reddy et al..$^{33}$ showed a single-rod construct stabilizing a sub-total L1 corpectomy with stackable carbon fiber-reinforced cage was significantly less rigid than intact, however addition of a second rod and a dual cross-connectors provided stability that approximated the intact spine. In a bisegmental L1 sub-total corpectomy model, Schreiber et al. ${ }^{34}$ noted that anterior plating only increased frontal and sagittal plane stiffness significantly over intact. Axial rotation ROM was increased, al- though not significantly. Additional posterior fixation was recommended for stabilization for questionable bone quality.

Comparing anterior fixation systems with posterior pedicle-based systems, Shono et al. ${ }^{35}$ and Schultheiss et al. ${ }^{36}$ both showed higher stability of the anterior dual-rod device over posterior intrapedicular fixation. Knop et al. ${ }^{24}$ showed similar stability in axial rotation and lateral bending between dual-rod and posterior pedicle screw fixation systems; however in neither case was axial rotation ROM less than intact. Flexion-extension ROM was reduced for the posterior system. Ulmar et al..$^{37}$ measured similar lateral bending stability between a fixed-angle screw anterior plate system and posterior pedicle screws. In flexion-extension and axial rotation, the posterior fixation was more rigid than the anterior plate. In axial rotation, both the plate and pedicle screw systems allowed greater ROM than intact, which was only improved by combining anterior and posterior fixation, which was recommended for rotationally unstable fractures. Bence et al. ${ }^{38}$ created a partial corpectomy with posterior ligament disruption at L1, which was reconstructed with iliac crest strut graft. They found both anterolateral plating and posterior fixation provided increased flexion-extension and lateral bending stability compared with the intact spine. The posterior system provided greater stability, but not statistically significantly so. Neither system provided axial rotation stability levels that reached intact. They recommended consideration of a combined anteriorposterior stabilization procedure for ligamentous disruptions of the posterior column in combination with vertebral fractures in the thoracolumbar junction. Bishop et al..$^{39}$ also concluded that combined anterior-posterior fixation should be considered in cases in which anterior column reconstruction alone may be insufficient. Although not directly investigated in this study, many studies have also shown the increased stability of combined anterior-posterior (circumferential) fixation over anterior-only fixation. $^{20,37,38,40-42}$

The results of this study suggest that supplemental fixation is needed with both expandable cage endcap designs, and that anterior plating yielded similar stability to bilateral pedicle screw instrumentation in all 
motion planes. The lack of clear difference between the endcap designs in the presence of supplemental fixation in this study suggests that the primary benefit of the large surface area, wide rectangular endcaps might be in resisting subsidence. In vitro studies investigating static ${ }^{12}$ and dynamic ${ }^{11}$ subsidence have demonstrated superior behavior with the rectangular endcaps over round endcaps. Further differences between the endcap designs with respect to potential range of motion endcaps afforded by the rectangular stability may be elucidated with cyclic testing. Similar stability between the anterior expandable cage with anterior plate instrumentation and bilateral pedicle screw fixation displayed in this study suggests anterior-only fixation may be sufficient, potentially obviating the need for a second stage posterior procedure with associated additional complications. However, long-term in vivo clinical studies will be needed to further evaluate the clinical success of this treatment method.

Limitations with the current study are similar to other cadaveric biomechanical studies. The sample size was limited to eight specimens. A larger number of specimens may have allowed smaller statistical differences between test conditions to be detected. Testing the corpectomy defect may have introduced variability to the specimens that could influence subsequent test results. The small standard deviations for the conditions with fixation (anterior plate of posterior pedicle screws) suggest that the rigidity of the fixation was more dominant than the underlying specimen flexibility; however the cage alone conditions may have been influenced. The order of testing may have also had an effect on the test results. For this reason, the order of testing the round and rectangular endcap conditions was altered between specimens to distribute this variability between the two endcap types. Specimens were tested without a follower load or axial load. This may underestimate the stability afforded by the different constructs; however trends are expected to be similar. In the clinical situation, all constructs may be more stable due to compressive loading caused by body weight and the surrounding musculature. Strengths of the study include testing non-osteoporotic human specimens to minimize variation related to implant-bone interface strength and using pure-moments to apply repeatable loading.

\section{Conclusions}

An anterior expandable cage alone with either round or rectangular endcaps provided significant stability as compared to corpectomy. In lateral bending and axial rotation, the rectangular endcaps provided significantly more stability than the round endcaps, however in flexion-extension the motion was similar between endcap types. The clinical implications of this warrants further investigation. Fixation with the anterior plate or bilateral pedicle screws provided the most rigid constructs although there were no significant differences in stability between the anterior plate and bilateral pedicle screw fixation methods with either endcap design. This finding suggests it may be appropriate to use an expandable cage in a sub-total corpectomy application using anterior-only supplemental fixation, without need for posterior or circumferential fixation. Choice of endcap type may be driven by other factors such as ability to resist subsidence.

\section{References}

1. Eck JC. Minimally invasive corpectomy and posterior stabilization for lumbar burst fracture. Spine $J$ 2011;11:904-8.

2. Muhlbauer M, Pfisterer W, Eyb R et al. Minimally invasive retroperitoneal approach for lumbar corpectomy and reconstruction. Technical note. Neurosurg Focus 1999;7:e4.

3. Smith WD, Dakwar E, Le TV et al. Minimally invasive surgery for traumatic spinal pathologies: a mini-open, lateral approach in the thoracic and lumbar spine. Spine 2010;35:S338-S346.

4. Uribe JS, Dakwar E, Le TV et al. Minimally invasive surgery treatment for thoracic spine tumor removal: a mini-open, lateral approach. Spine 2010;35:S347-S354.

5. Scheufler KM. Technique and clinical results of minimally invasive reconstruction and stabilization of the thoracic and thoracolumbar spine with expandable cages and ventrolateral plate fixation. $\mathrm{Neu}$ rosurgery 2007;61:798-808.

6. Amaral R, Marchi L, Oliveira L et al. Acute lum-

Downloaded from http://ijssurgery.com/ by guest on April 25, 2023 
bar burst fracture treated by minimally invasive lateral corpectomy. Case Rep Orthop 2013;2013:953897. 7. Adkins DE, Sandhu FA, Voyadzis JM. Minimally invasive lateral approach to the thoracolumbar junction for corpectomy. J Clin Neurosci

2013;20:1289-94.

8. Tomycz L, Parker SL, McGirt MJ. Minimally invasive transpsoas $\mathrm{L} 2$ corpectomy and percutaneous pedicle screw fixation for osteoporotic burst fracture in the elderly: technical report. J Spinal Disord Tech 2015;28:53-60.

9. Park WM, Park YS, Kim K et al. Biomechanical comparison of instrumentation techniques in treatment of thoracolumbar burst fractures: a finite element analysis. J Orthop Sci 2009;14:443-9.

10. Palm WJ, Rosenberg WS, Keaveny TM. Load transfer mechanisms in cylindrical interbody cage constructs. Spine 2002;27:2101-7.

11. Deukmedjian AR, Manwaring J, Le TV et al. Corpectomy cage subsidence with rectangular versus round endcaps. J Clin Neurosci 2014;21:1632-6.

12. Pekmezci M, McDonald E, Kennedy A et al. Can a novel rectangular footplate provide higher resistance to subsidence than circular footplates? An ex vivo biomechanical study. Spine

2012;37:E1177-E1181.

13. Grant JP, Oxland TR, Dvorak MF. Mapping the structural properties of the lumbosacral vertebral endplates. Spine 2001;26:889-96.

14. Pimenta L, Turner AW, Dooley ZA et al. Biomechanics of lateral interbody spacers: going wider for going stiffer. ScientificWorldJournal 2012;2012:381814.

15. Sasso RC, Best NM, Reilly TM et al. Anterioronly stabilization of three-column thoracolumbar injuries. J Spinal Disord Tech 2005;18 Suppl:S7-14.

16. Dooley ZA, Turner AW, Cornwall GB. Multiaxial spine testing apparatus: system characterization by evaluation of analog and cadaveric lumbar spines. Int $J$ of Experimental and Computational Biomechanics 2013;2:189-203.

17. Hitchon PW, Goel VK, Rogge TN et al. In vitro biomechanical analysis of three anterior thoracolumbar implants. J Neurosurg 2000;93:252-8.

18. Brodke DS, Gollogly S, Bachus KN et al. Anterior thoracolumbar instrumentation: stiffness and load sharing characteristics of plate and rod systems.
Spine 2003;28:1794-801.

19. Buttermann GR, Freeman AL, Beaubien BP. In vitro biomechanics of an expandable vertebral body replacement with self-adjusting end plates. Spine J 2010;10:1024-31.

20. Kallemeier PM, Beaubien BP, Buttermann GR et al. In vitro analysis of anterior and posterior fixation in an experimental unstable burst fracture model. J Spinal Disord Tech 2008;21:216-24.

21. Lim TH, An HS, Hong JH et al. Biomechanical evaluation of anterior and posterior fixations in an unstable calf spine model. Spine 1997;22:261-6.

22. Gurwitz GS, Dawson JM, McNamara MJ et al. Biomechanical analysis of three surgical approaches for lumbar burst fractures using short-segment instrumentation. Spine 1993;18:977-82.

23. Cardenas RJ, Javalkar V, Patil S et al. Comparison of allograft bone and titanium cages for vertebral body replacement in the thoracolumbar spine: a biomechanical study. Neurosurgery 2010;66:314-8.

24. Knop C, Lange U, Bastian L et al. Threedimensional motion analysis with Synex. Comparative biomechanical test series with a new vertebral body replacement for the thoracolumbar spine. Eur Spine J 2000;9:472-85.

25. Pflugmacher R, Schleicher P, Schaefer J et al. Biomechanical comparison of expandable cages for vertebral body replacement in the thoracolumbar spine. Spine 2004;29:1413-9.

26. Dai LY, Jiang LS, Jiang SD. Anterior-only stabilization using plating with bone structural autograft versus titanium mesh cages for two- or three-column thoracolumbar burst fractures: a prospective randomized study. Spine 2009;34:1429-35.

27. McDonough PW, Davis R, Tribus $\mathrm{C}$ et al. The management of acute thoracolumbar burst fractures with anterior corpectomy and Z-plate fixation. Spine 2004;29:1901-8.

28. Wilson JA, Bowen S, Branch CL, Jr. et al. Review of 31 cases of anterior thoracolumbar fixation with the anterior thoracolumbar locking plate system. Neurosurg Focus 1999; 7:e1.

29. Hitchon PW, Torner J, Eichholz KM et al. Comparison of anterolateral and posterior approaches in the management of thoracolumbar burst fractures. J Neurosurg Spine 2006;5:117-25.

30. Hitchon PW, Brenton MD, Serhan $\mathrm{H}$ et al. In 
vitro biomechanical studies of an anterior thoracolumbar implant. J Spinal Disord Tech

2002;15:350-4.

31. Disch AC, Knop C, Schaser KD et al. Angular stable anterior plating following thoracolumbar corpectomy reveals superior segmental stability compared to conventional polyaxial plate fixation. Spine 2008;33:1429-37.

32. Chang UK, Lim J, Kim DH. Biomechanical study of thoracolumbar junction fixation devices with different diameter dual-rod systems. J Neurosurg Spine 2006;4:206-12.

33. Reddy CG, Magnetta M, Dahdaleh NS et al. An in vitro biomechanical comparison of single-rod, dual-rod, and dual-rod with transverse connector in anterior thoracolumbar instrumentation. Neurosurgery 2012;70:1017-23.

34. Schreiber U, Bence T, Grupp T et al. Is a single anterolateral screw-plate fixation sufficient for the treatment of spinal fractures in the thoracolumbar junction? A biomechanical in vitro investigation. Eur Spine J 2005;14:197-204.

35. Shono Y, McAfee PC, Cunningham BW. Experimental study of thoracolumbar burst fractures. A radiographic and biomechanical analysis of anterior and posterior instrumentation systems. Spine 1994;19:1711-22.

36. Schultheiss M, Hartwig E, Kinzl L et al. Axial compression force measurement acting across the strut graft in thoracolumbar instrumentation testing. Clin Biomech 2003;18:631-6.

37. Ulmar B, Erhart $S$, Unger $S$ et al. Biomechanical analysis of a new expandable vertebral body replacement combined with a new polyaxial antero-lateral plate and/or pedicle screws and rods. Eur Spine J 2012;21:546-53.

38. Bence T, Schreiber U, Grupp T et al. Two column lesions in the thoracolumbar junction: anterior, posterior or combined approach? A comparative biomechanical in vitro investigation. Eur Spine $J$ 2007;16:813-20.
39. Bishop FS, Samuelson MM, Finn MA et al. The biomechanical contribution of varying posterior constructs following anterior thoracolumbar corpectomy and reconstruction. J Neurosurg Spine 2010;13:234-9.

40. Acosta FL, Jr., Buckley JM, Xu Z et al. Biomechanical comparison of three fixation techniques for unstable thoracolumbar burst fractures. Laboratory investigation. J Neurosurg Spine 2008;8:341-6. 41. Eichholz KM, Hitchon PW, From A et al. Biomechanical testing of anterior and posterior thoracolumbar instrumentation in the cadaveric spine. Invited submission from the Joint Section Meeting on Disorders of the Spine and Peripheral Nerves, March 2004. J Neurosurg Spine 2004;1:116-21. 42. Vahldiek MJ, Panjabi MM. Stability potential of spinal instrumentations in tumor vertebral body replacement surgery. Spine 1998;23:543-50.

\section{Disclosures}

Dr. Eastlack is a consultant to, has direct stock ownership in and has provided expert testimony on behalf of NuVasive, Inc.; Dr. Mundis is a consultant to and received royalties from NuVasive. Dr. Mundis is also a board member of SOLAS. Drs. Cornwall and Turner are employees of and have direct stock ownership in NuVasive. Dr. Moazzaz has no disclosures relevant to this manuscript.

\section{Corresponding Author}

Robert Eastlack, MD, Scripps Clinic Division of Orthopedic Surgery, La Jolla, CA.

reastlack@gmail.com.

Published 22 October 2015.

This manuscript is generously published free of charge by ISASS, the International Society for the Advancement of Spine Surgery. Copyright @ 2015 ISASS. To see more or order reprints or permissions, see http://ijssurgery.com. 